\title{
Liquid diets for Crohn's disease
}

M O'Sullivan, C O’Morain

\section{Enteral diets: primary therapeutic role}

In the early 1970 s, disease modifying effects of an elemental diet in Crohn's disease (CD) were observed. The first controlled study in 1984 confirmed that an elemental diet was as effective as steroids in inducing remission in acute CD. ${ }^{1}$ Several subsequent studies supported this primary therapeutic effect for both elemental and polymeric enteral diets (see review ${ }^{2}$ ). Pooling the data however has shown a less favourable outcome with three meta-analyses similarly concluding that corticosteroids were more effective than enteral diet therapy. A heterogeneous study mix may not be representative of the clinical situation. Data, from a single centre spanning 10 years of enteral diet therapy supported remission rates equal to that of drug therapy. ${ }^{3}$ In addition to therapeutic effect, liquid diets for acute $\mathrm{CD}$ offer an unrivalled safety profile and significant nutritional benefits. We consider these diets as ideal therapy in paediatric CD, especially in the presence of malnutrition or growth impairment, and in patients with severe drug induced side effects. Patients with CD typically relapse in the longer term, irrespective of the therapeutic approach, and therefore maintenance and retreatment strategies for diet induced remission should be more fully investigated.

\section{Enteral diets: mode of therapeutic effect}

The clinical response to an enteral diet has been associated with a reduction in disease activity scores and in inflammatory markers. Decreased intestinal permeability, histological healing, and downregulation of mucosal proinflammatory cytokines ${ }^{4}$ have also been reported. To date, the mechanisms underlying this therapeutic response remain unclear. Proposed theories include reduced antigenic load, provision of trophic amino acids, alterations in gut flora, and immune modulating effects of fatty acids supplied by the feed. The quantity and type of fat in a liquid feed may be an important determinant of therapeutic response, a premise supported by reports of aberrant fatty acid profiles in $\mathrm{CD}^{5}$ and better therapeutic outcome with lower fat and fat modified feeds.

\section{Enteral diets: nutritional role}

Undernutrition, weight loss, and poor nutritional status have been reported at all stages of CD - at diagnosis,

Department of Gastroenterology, Adelaide and Meath Hospital, Trinity College, Dublin 24, Ireland

Correspondence to: $\operatorname{Dr} M$ O'Sullivan. gastroenterology@ amnch.ie during active disease, and in remission. Undernutrition further complicates CD; moreover, villous atrophy ${ }^{6}$ and gastrointestinal dysfunction associated with severe undernutrition may have direct negative implications for mucosal healing. In children and adolescents with $\mathrm{CD}$, the effects of undernutrition combined with corticosteroid therapy have a severe negative impact on linear growth. An estimated $70 \%$ of patients with early onset Crohn's fail to meet their expected height by adulthood. These are strong grounds to favour enteral nutrition as primary therapy in paediatric CD. Furthermore, use of supplemental enteral nutrition after diet induced remission has been associated with improved linear growth and prolonged remission. Careful nutritional monitoring and appropriate intervention are clearly required in both children and adults and at all stages of disease.

Enteral diet: a Crohn's disease specific formula Specific constituents of an enteral feed may aid mucosal repair and protective mechanisms in CD. There has long been an interest in the role of glutamine, although a recent controlled trial could find no benefit associated with a glutamine enriched polymeric formula in the treatment of $\mathrm{CD}^{7}{ }^{7}$ In another recent study, butyrate was reported to downregulate inflammatory cytokine expression via inhibition of nuclear factor $\kappa \mathrm{B}$ in $\mathrm{CD} .{ }^{8}$ In the future, these and other elements, including pre- and probiotics, short chain fatty acids, and growth factors may have a place in a CD specific formula. In the face of increasingly advanced immune modulatory therapies, enteral diets may seem rather mundane. Nevertheless, these diets may well offer an ideal and safe mode of delivery of immune modulatory nutrients/substrates directly to the gastrointestinal mucosa.

1 O' Morain C, Segal AW, Levi AJ. Elemental diet as primary treatment of acute Crohn's disease: a controlled trial. BMF 1984;288:1859-62.

O' Sullivan M, O'Morain C. Nutritional therapy in Crohn's disease. Inflamm Bowel Dis 1998;4:45-53.

3 Teahon K, Bjarnason I, Pearson M, et al. Ten years' experience with an elemental diet in the management of Crohn's disease. Gut 1990;31: $1133-7$

4 Fell JM, Paintin M, Arnaud-Battandier F, et al. Mucosal healing and a fall in mucosal pro-inflammatory cytokine mRNA induced by a specific oral polymeric diet in paediatric Crohn's disease. Aliment Pharmacol Ther 2000;14:281-9.

5 Geerling BJ, v Houwelingen AC, Badart-Smook A, et al. The relation between antioxidant status and alterations in fatty acid profile in patients with Crohn disease and controls. Scand $\mathcal{F}$ Gastroenterol 1999; 34:1108-16.

6 Winter TA, Lemmer ER, O' Keefe S, et al. The effect of severe undernutrition, and subsequent refeeding on digestive function in human patients. Eur $\mathcal{F}$ Gastroenterol Hepatol 2000;12:191-6.

7 Akobeng AK, Miller V, Stanton J, et al. Double-blind randomized controlled trial of glutamine-enriched polymeric diet in the treatment

active Crohn's disease. F Pediatr Gastroenterol Nutr 2000;30:78-84.

8 Segain JP, de La Bletiere DR, Bourreille A, et al. Butyrate inhibits inflammatory responses through NFKB inhibition: implications for
Crohn's disease. Gut 2000;47:397-403. 